No. 4760 January 21, 1961

\section{Seventeenth-Century Bronze Finds in Eastern Nigeria}

AN interim report of excavations undertaken at Igbo-Ukwu, Eastern Nigeria, by 'Thurstan Shaw, appears in the November issue of Man. About twenty years ago some interesting finds, including bronze vessels, were unearthed by an African called Isaiah Anozio when digging out an underground cistern. Some of these objects are now in the museums at Jos and Lagos, and the facts of the find were duly reported in Man. Thurstan Shaw has now undertaken systematic investigations at the site and many more objects have been recovered from this and another nearby compound. They include pots, bowls, a swordhilt and scabbard, ornaments, rings, and a coiled snake on a spike, all in bronze. Of the two sites the first seems to have been a vessel or regalia store-place, and the second a burial. It is suggested that they were both connected with the former Eze Nri-the priest King of Umueri, who brought from the region of Idah an intrusive culture into Tboland. A seventeenth-century date and African workmanship are here tentatively postulated.

\section{Indians of the Western Prairies}

The Department of Northern Affairs and National Resources, Canada, has recently issued a bulletin in its Anthropological Series entitled Indian Days on the Western Prairies, which has been prepared by Marius Barbeau (Bulletin No. 163. Anthropological Series, No. 46. Pp. vi +234 and 165 plates. Ottewa: Queen's Printer, 1960. 4 dollars). The Bulletin is full of Indian tales and is well illustrated, sometimes in colour. But the work, of course, is a serious contribution to the study of the old inhabitants of the western prairies. There is a long introduction, where a general account of the tribes and their problems is given and the difficulties facing them are discussed. Most of the volume, however, is devoted to stories told by the Indians themselves, which give a vivid idea of the outlook on life of these people at the time of the coming of the white man, and of how they reacted to his arrival. There are a great number of illustrations of scenes and designs, mostly taken from paintings on skins. There are also portraits drawn in eharacteristic style by Langdon Kihn. The volume is of great value to anyone wishing to learn something of the civilization of these inter. esting peoples.

\section{Diagnosis of Yaws}

As increasing progress is made in the eradication of yaws in many countries, it becomes increasingly important to differentiate as clearly as possible between skin and other lesions not caused by yaws and those yaws lesions which they may closely resemble. At all stages of a mass campaign for the eradication of yaws, the clinical diagnosis should be as accurate as circumstances permit. However, in view of the limited time available in the initial treatment surveys and of the simple training given to many of the field staff, a certain proportion of diagnoses-probably about 10 per cent-may be expected to be erroneous. Such errors are all the easier to make as the skin has a limited number of reaction patterns, so that similar lesions may result from different causes. In the later stages of an eradication campaign, the manifestations of yaws have largely disappeared as a result of mass treatment with penicillin. It is then that many lesions not due to yaws become prominent, and at this stage accuracy of diagnosis assumes particular importance. The lesions of yaws were fully illustrated in C. J. Hackett's An International Nomenclature of Yaws Lesions, published by the World Health Organization in 1957. A new monograph, written by the same author in collaboration with Dr. L. J. A. Loewenthal, is intended as a companion volume to the earlier publication, and was prepared in response to requests for an illustrated handbook which would assist field workers in making accurate diagnoses (World Health Organization. Monograph Serias No. 45: Differential Diagnosis of Yaws. Pp. 88 (52 figures). (Geneva: World Health Organization; London : H.M. Stationery Office, 1960.) 10 Swiss francs ; 17s. $6 d . ; 3.25$ dollars.

\section{Hearing in Cetaceans}

THE skull of the Cetacen differs widely from tho usual mammalian pattern; the relative sizes and positions of the bones forming it are much modified, and in many species they show a high degree of asymmetry. A complicated system of air sinuses connected with the Eustacian tube is associated with extensive venous plexuses in the basicranial region, the tympano-periotic bones are dissociated from the skull, and the bones of the middle ear with the tympanic membrane are also highly modified. Such peculiar conditions have long attracted the attention of comparative anatomists, whose observations are scattered through the literature of cetology. A recent paper (Fraser, F. C., and Purves, P. E., "Hearing in Cetaceans", Bull. Brit. Mus. (Nat. Hist.), 7, No. 1 ; 1960) reviews the history of the subject, and gives detailed comparative descriptions of the anatomy of the cetacean head based on original dissections, injected preparations, and radiographs. The authors had access to a large amount of unique material and have brilliantly illuminated much that was previously obscure. They have not, however, confined themselves to descriptive anatomy, for they have devised and carried out numerous elegant experiments to ascertain the functions of the various anatomical structures in the physiology of hearing. They have been able to show that the generally accepted theory which claims the Cetacea hear by bone conduction is not only erroneous but also impossible, and that in all the cetaceans the sense of hearing is the most important of the special senses. These points and many others are lucidly described and discussed in this scholarly and well-written paper, which is illustrated with numerous excellent plates. It is by far the most important work on the anatomy and physiology of the Cetacea to appear since Scholander's classic paper of 1940 .

\section{Effects of Maleic Hydrazide on Rust Fungi}

SOME interesting differential effects of maleic hydrazide on the growth of leaf and stem rusts of wheat are reported by D. J. Samborski et al. (Canad. J. Bot., 38, 1 ; 1960). The effect of this substance was investigated, using intact plants supplied with maleic hydrazide through the roots, detached leaves floated on solutions of maleic hydrazide, and spores germinated on maleic hydrazide solutions in agar. In each instance the growth of leaf rust was inhibited at concentrations of maleic hydrazide which had no effect on the growth of stem rust. Some resistant wheat varieties became susceptible to rust after treatments with levels of maleic hydrazide which 